\title{
Shifted T-cell polarisation after agricultural dust exposure in mice and men
}

\author{
P Robbe, ${ }^{1,2}$ EAJ Spierenburg, ${ }^{3}$ C Draijer, ${ }^{2,4}$ CA Brandsma ${ }^{1,2}$ E Telenga, ${ }^{2,5}$ \\ AJM van Oosterhout, ${ }^{2,6} \mathrm{M}$ van den Berge, ${ }^{2,5} \mathrm{M}$ Luinge, ${ }^{1,2}$ BN Melgert, ${ }^{2,4}$ \\ D Heederik, ${ }^{3}$ W Timens, ${ }^{1,2}$ IM Wouters, ${ }^{3}$ MN Hylkema ${ }^{1,2}$
}

\begin{abstract}
- Additional material is published online only. To view please visit the journal online (http://dx.doi.org/10.1136/ thoraxjnl-2013-204295)

For numbered affiliations see end of article.

\section{Correspondence to} Dr Machteld N Hylkema, Department of Pathology, University of Groningen, University Medical Center Groningen, Hanzeplein 1, Groningen $9713 \mathrm{GZ}$

The Netherlands; m.n.hylkema@umcg.nl
\end{abstract}

Received 5 August 2013 Revised 6 January 2014 Accepted 28 January 2014 Published Online First 17 February 2014

\section{ABSTRACT}

Rationale A low prevalence of asthma and atopy has been shown in farmers and agricultural workers. However, in these workers, a higher prevalence of respiratory symptoms has been reported, in which T helper 1 (Th1) and/or Th17 responses may play a role. Aim We investigated the effect of exposure to dust extracts (DEs) from different farms on airway inflammation and T-cell polarisation in a mouse model and assessed T-cell polarisation in agricultural workers from the same farms.

Methods DEs were prepared from settled dust collected at cattle and pig farms and bulb and onion industries. Mice were exposed to phosphate-buffered saline (PBS), DEs, house dust mite (HDM) or HDM+DE via nasal instillation, four times per week during 5 weeks. Hyperresponsiveness, airway inflammation, IgE levels and T-cell polarisation were assessed. Th-cell and $T$ cytotoxic (Tc)-cell subsets were investigated in peripheral blood samples from 33 agricultural workers and 9 non-exposed controls.

Results DEs induced interleukin(IL)-17, IL-1 $\beta$ and IL-6 in mouse lung homogenates. DE-exposed mice had more mixed inflammatory infiltrates in the lungs, and more neutrophils compared with PBS-exposed mice. DEs protected against the HDM-induced Th2 response and methacholine hyperresponsiveness. Interestingly, occupationally exposed humans had higher frequencies of Th cells spontaneously expressing IL-17 and interferon $\gamma$ compared with controls.

Conclusion Chronic exposure to different types of farm dust induces a Th/Tc-17 inflammatory response in mice and agricultural workers. This may contribute to the low prevalence of Th2-related diseases but may constitute a risk for other chronic respiratory diseases.

\section{INTRODUCTION}

Several studies have shown that farmers and agricultural workers (AWs) have a high prevalence of respiratory symptoms related to chronic bronchitis and COPD. ${ }^{1-3}$ However, it is well recognised that exposure to farm environments has a protective effect against the development of $\mathrm{T}$ helper 2 (Th2)-related allergic diseases. ${ }^{4-7}$ Dose-response relations have been described for occupational endotoxin exposure in association with protection from atopic sensitisation ${ }^{8-10}$ and allergic asthma, ${ }^{11}$ whereas positive associations with increased airway responsiveness $^{89}$ and non-allergic asthma have also been reported. ${ }^{11}$
Key messages

What is the key question?

- What is the effect of chronic exposure to farm environments on T-cell subsets and lung inflammation in mice and men?

What is the bottom line?

- Chronic exposure to farm environments may protect against Th2 responses but induces Th17 responses in mice and men.

\section{Why read on?}

- This study reveals that chronic exposure to different types of farm dust induces a Th17 inflammatory response in mice and agricultural workers, which may contribute to the protection against Th2-related diseases but may increase the risk for other chronic respiratory diseases.

In mice, exposure to a mixed farm dust extract from cattle and goat stables protected mice from the development of ovalbumine (OVA)-induced asthma features. ${ }^{12}$ Moreover, a shift in the T-cell response towards Th1 and Th17 subsets has been observed in mice after repetitive exposure to dust extract derived from pig confinement. ${ }^{13}$ In humans, exposure to swine confinement induced levels of IL-17 and IL-17 expressing lymphocytes in bronchoalveolar lavage (BAL) fluid. ${ }^{14}{ }^{15}$ Interestingly, the Th17 response has been shown to be associated with the development of non-allergic or neutrophilic asthma in transgenic mice overexpressing ROR $\gamma \mathrm{t} .{ }^{16}$ Hence, a shifted T-cell response could underlie the observed paradoxical effect of exposure to the farm environment in mice and humans.

Depending on the agricultural sector, the workrelated microbial exposure can vary greatly. ${ }^{11}{ }^{17}$ However, to date, the effects of agricultural dust exposures from diverse sources on T-cell differentiation and the inflammatory response are unclear. Therefore, we determined whether dusts from two farms (cattle and pig) and two agricultural-related environments (onion and bulb industry) changed T-cell responses and the inflammatory profile in mice. A clinically relevant house dust mite (HDM) murine model of experimental asthma was used to 
investigate the protective effect of different types of farm dust exposure on the HDM-induced allergic airway inflammation. In addition, human Th-cell subsets were assessed in occupationally exposed subjects from the same environmental settings as the dust used in the mouse experiments and compared with nonexposed subjects.

\section{MATERIAL AND METHODS \\ Animal study design}

Specific pathogen-free female BALB/c mice $(n=8$ per experimental group, 8 weeks old) were anesthetised with isoflurane and intranasally exposed to each different dust extract (DE; details below; DE exposure: $1 \mathrm{mg} / \mathrm{mL}$ in phosphate-buffered saline (PBS), $50 \mu \mathrm{L} /$ day), house dust mite (HDM exposure: $40 \mu \mathrm{g} /$ day in $50 \mu \mathrm{L} \mathrm{PBS})$ or PBS $(50 \mu \mathrm{L} /$ day $)$ as a control, four times per week, during five consecutive weeks. To investigate the protective effect of dust exposure, mice were exposed to the combination of HDM and each type of DE. See online supplement (figure S1). Mice had access to standard food and water ad libitum. All animal protocols were approved by the Institutional Animal Care and Use Committee of the University of Groningen (permit number 4788E).

\section{Dust extracts}

Settled dust was collected from farms and agricultural industries in the Netherlands, and was extracted applying a protocol adapted from Peters et al. ${ }^{12}$ For details, see online supplement. The endotoxin concentrations of the different DEs were assessed using the limulus amebocyte lysate assay (Lonza) as described previously. ${ }^{18}$ Fungal extracellular polysaccharide (EPS) levels were measured using a sandwich ELISA. ${ }^{19}$ Observed lipopolysaccharide and EPS levels are presented in table 1.

\section{House dust mite}

HDM consisted of crushed whole bodies from Dermatophagoides pteronyssinus (Greer Laboratories). The endotoxin content according to the manufacturer was $12.05 \mathrm{sEU} / \mathrm{mg}$.

\section{Assessment of methacholine responsiveness}

One day after the last exposure, methacholine (MCh) responsiveness was assessed as changes in enhanced pause (Penh) in conscious, spontaneously breathing animals using a whole-body plethysmography system (Buxco Electronics) as described previously. $^{20}$ The concentration of MCh inducing a $200 \%$ increase in Penh (PC200) was calculated.

\section{Tissue collection}

After 5 weeks of exposure, mice were anaesthetised and sacrificed by cardiac exsanguination. Serum was collected and kept at $-20^{\circ} \mathrm{C}$ until use. The left lung lobe was snap frozen and kept at $-80^{\circ} \mathrm{C}$ until preparation of lung homogenates for cytokine

Table 1 Endotoxin and extracellular polysaccharide (EPS) levels measured in the different types of farm dust extracts at $1 \mu \mathrm{g} / \mu \mathrm{L}$

\begin{tabular}{llc}
\hline Type of farm dust & Endotoxin (EU/mL) & EPS (EPS units/mL) \\
\hline Flower bulb & 11872 & 2330 \\
Onion & 15346 & 420 \\
Cattle & 20101 & 278 \\
Pig & 31269 & 2240 \\
\hline
\end{tabular}

analysis. For details, see online supplement. Right lung lobes were carefully inflated with $0.9 \mathrm{~mL} 50 \%$ Tissue Tek, OCT (Sacura) in PBS, and three of the of the four lobes were snap frozen and stored at $-80^{\circ} \mathrm{C}$ until use, while the smallest right lung lobe was zinc fixed and embedded in paraffin.

\section{Measurement of HDM-specific serum IgE}

House dust mite-specific IgE was measured in serum as described previously. ${ }^{21}$

\section{Cytokines}

Concentrations of interleukin (IL)-1 $\beta$, IL-4, IL-5, IL-6, IL-13 and IL-17 were measured in lung homogenates by 6-plex ELISA system (Affimetrix), or standard ELISA (eBioscience) for interferon $\gamma(\mathrm{IFN} \gamma)$.

\section{Semi quantitative evaluation of inflammatory infiltrates}

Sections $(3 \mu \mathrm{m})$ of zinc-fixed and paraffin-embedded lung tissue were stained using hematoxylin and eosin. Semi-quantitative scores for degree of inflammation from 0 to 3 were determined by a blinded reviewer. For details, see online supplement and figure S2.

\section{Immunohistochemistry}

Cryosections of lung tissue, $4 \mu \mathrm{m}$ thick, were stained with specific antibodies to determine the presence of T cells, Th17, T cytotoxic 17 (Tc17), $\gamma \delta$ T cells, B cells, neutrophils and macrophages. For details, see online supplement. Eosinophils were determined with peroxidase enzymehistochemistry using diaminobenzidine (DAB, Sigma Aldrich) as substrate.

For quantitative analysis, neutrophils, Th17 and Tc17 cells were counted manually and numbers were corrected for the total area of lung tissue section as assessed by morphometric analysis using Aperio ImageScope viewing software V.11.2.0.780.

\section{Human study population}

T-cell subsets in human subjects were studied in 33 non-smoking Dutch AWs (pig and cattle farmers and onion and flower bulb industry workers), with known high dust and microbial exposure, derived from the follow up of the initial OMeGA study, ${ }^{17}$ and 9 non-exposed controls derived from the NORM cohort. In the NORM study, healthy never and current smokers were included and extensively clinically characterised (NCT00848406). Ten nonsmoking subjects were randomly selected per work environment from the follow-up cohort (with the exception of pig farmers of whom only three non-smokers were available) and nine nonsmoking non-exposed controls were matched for age and gender. Hereafter, farmers and agricultural industry workers will be referred to as 'agricultural workers' (AWs). The study protocol was approved by the institutional ethics committee and all participants gave their written informed consent.

\section{Sample preparation and in vitro stimulation}

Peripheral blood mononuclear cells (PBMCs) were isolated using standard density gradient centrifugation and were stored in aliquots in liquid nitrogen. After thawing, cells were washed and resuspended in warm RPMI1640 with 10\% fetal calf serum (FCS) and $8-10 \times 10^{5}$ cells per well were stimulated overnight with $25 \mathrm{ng} / \mathrm{mL}$ phorbol myristate acetate (PMA, Sigma-Aldrich) and $1 \mu \mathrm{g} / \mathrm{mL}$ calcium ionophore (Ca-Io, Sigma-Aldrich) at $37^{\circ} \mathrm{C}, 5 \%$ $\mathrm{CO}_{2}$. Monensin $(2 \mu \mathrm{g} / \mathrm{mL}$, Sigma-Aldrich) was added to each sample to inhibit cytokine secretion. As a control, one sample of 

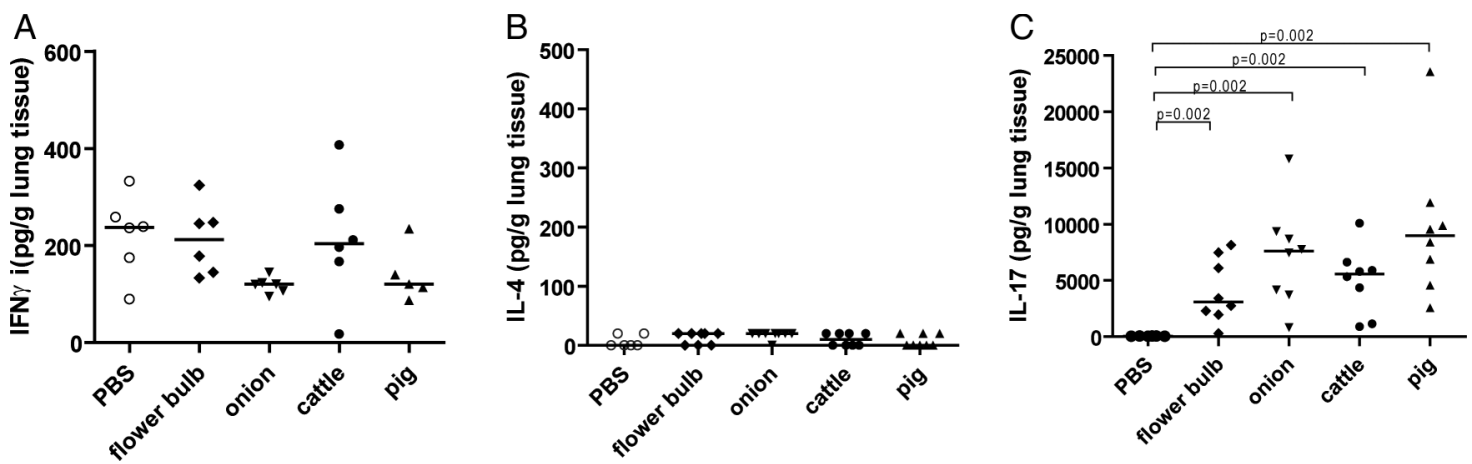

Figure 1 Cytokine levels in lung tissue. Levels of (A) interferon $\gamma$ (IFN $\gamma$ ), (B) interleukin (IL)-4 and (C) IL-17 in lung tissue from mice exposed to phosphate-buffered saline (PBS) or dust extracts derived from cattle or pig farms or flower bulb or onion industries ( $n=6-8$ per group).

A

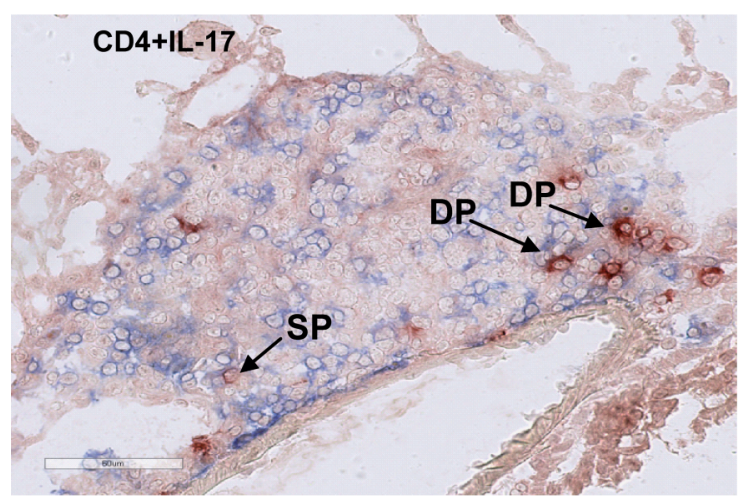

C

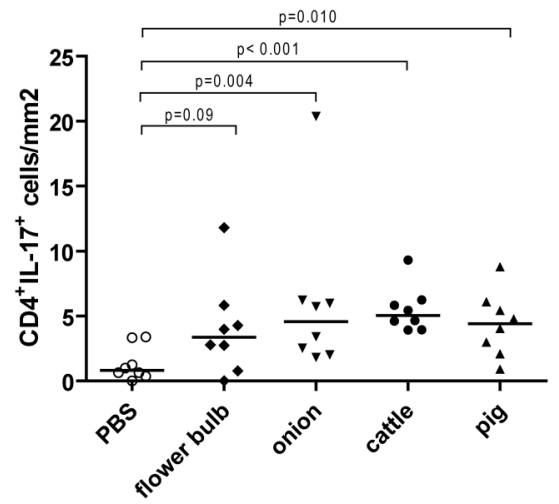

E

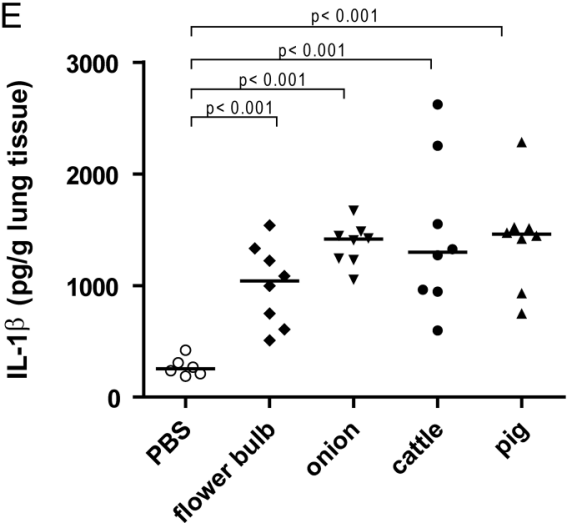

B

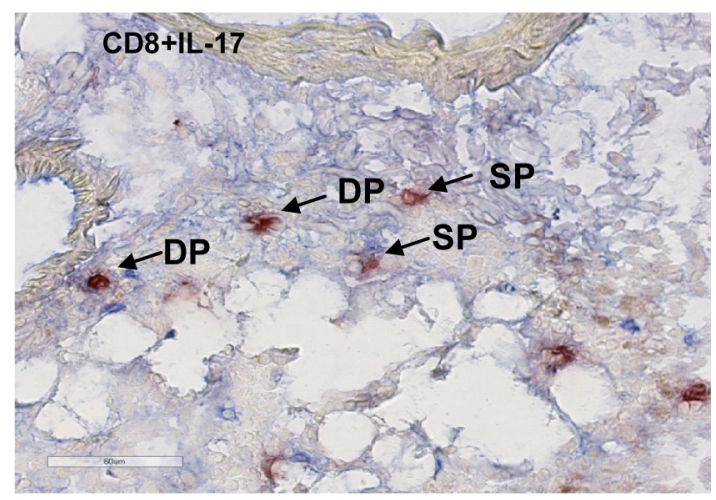

D

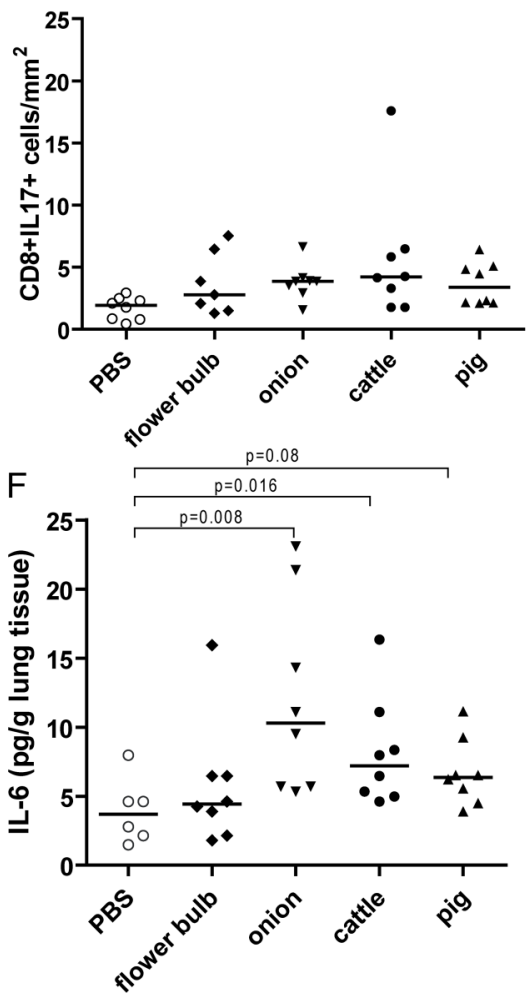

Figure 2 IL-17-producing T cells in lung tissue of mice exposed to dust extracts (DEs) from cattle farms are shown by immunohistochemical staining of (A) CD4 (blue) and interleukin (IL)-17 (red), and (B) CD8 (blue) and IL-17 (red) positive cells. Arrows indicate IL-17 single positive (SP) and double positive (DP) cells (C) numbers of CD4IL-17 and (D) CD8IL-17 double positive cells in lung tissue, (E) IL-1 $\beta$ and (F) IL-6 levels in lung tissue from mice exposed to PBS or DEs from cattle or pig farm or flower bulb or onion industries ( $n=6-8$ per group). 

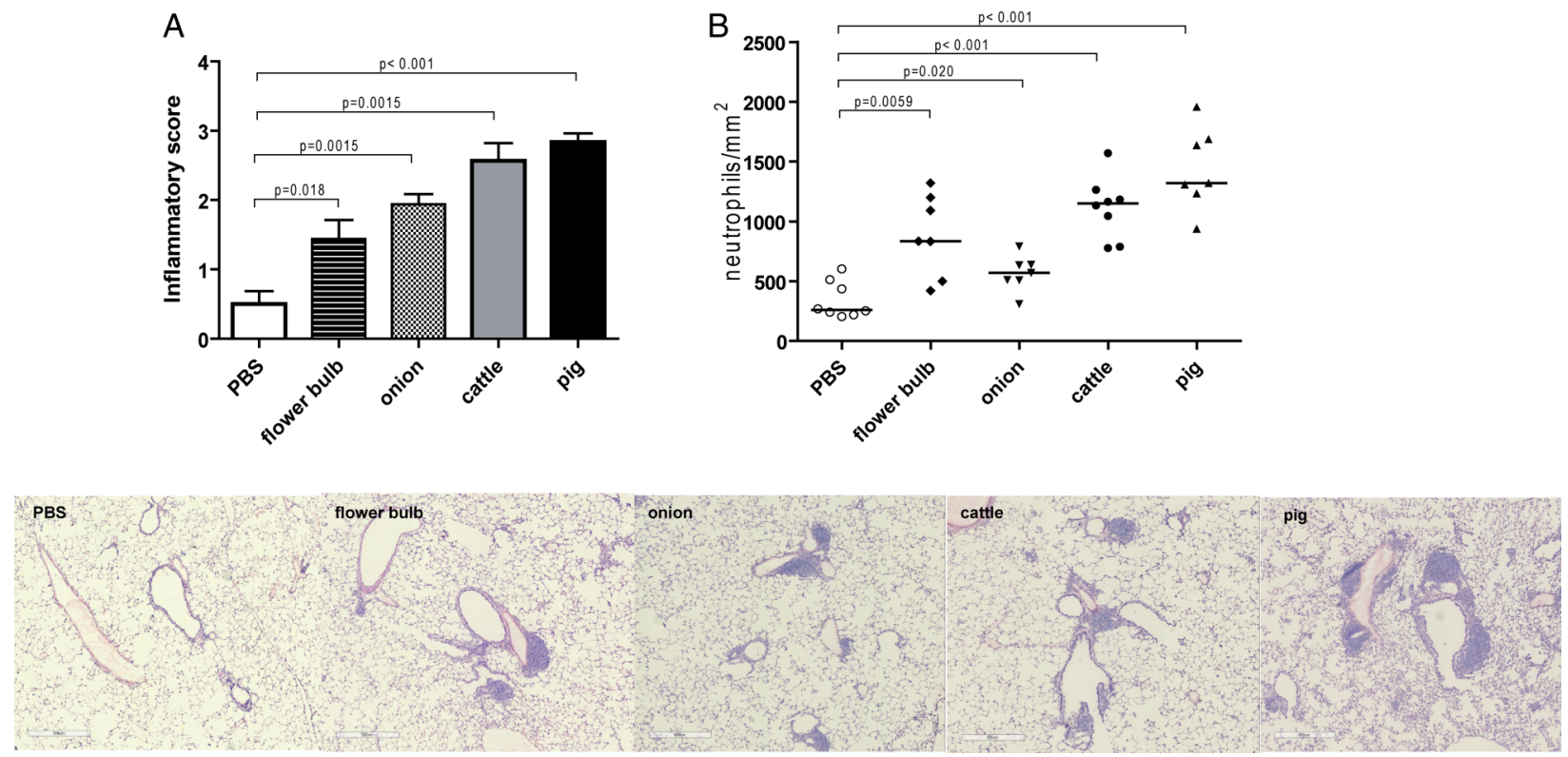

Figure 3 (A) Inflammatory scores and (B) numbers of neutrophils in lung tissue from mice exposed to phosphate-buffered saline (PBS) or dust extracts from cattle or pig farm or flower bulb or onion industries ( $n=6-8$ per group) Representative pictures of hematoxylin and eosin-stained lung sections of mice from each exposure group are shown.

each subject was cultured overnight in complete RPMI at $37^{\circ} \mathrm{C}$, $5 \% \mathrm{CO}_{2}$ without stimulation. For details, see online supplement.

\section{Immunofluorescent staining and flow cytometric analysis}

After stimulation, the cells were washed in $2 \%$ bovine serum albumin/PBS and counted. $10^{6}$ cells were used for the flowcytometry staining. Flowcytometry data were analysed using FlowJo software V.7.6.5 (Tree Star Inc). For details, see online supplement and figure S6.

\section{Statistical analysis}

Data are presented as median unless stated otherwise. The nonparametric Kruskal-Wallis test was used to assess whether differences between groups existed, followed by a Mann-Whitney U test for post hoc analysis. Different DE exposures were compared to control, and HDM+DE exposed groups were compared with the HDM-exposed group. All analyses were performed using GraphPad Prism V.5.0, and differences were considered statistically significant at two-sided $\mathrm{p}$ values less than 0.05 .

\section{RESULTS}

DE exposure induces IL-17 in mouse lung tissue

To determine the effect of DE exposure on the immune response in murine lung, the presence of Th1 (IFN $\gamma$ ), Th2 (IL-4) and Th17 (IL-17A) cytokines was investigated in lung homogenates of mice exposed to different types of DE or to PBS as control. Mice exposed to all different types of DE had higher levels of IL-17 in the lungs compared with PBS-exposed mice (figure 1C). DE exposure had no effect on IFN $\gamma$ or IL-4 levels (figure 1A,B).

\section{DE exposure induces Th17 in mouse lung tissue}

The source of IL-17 in lung tissue was investigated. All IL-17-positive cells were also positive for CD3, and thus of T-cell origin. Quantitative analysis revealed higher numbers of Th17 cells $\left(\mathrm{CD}^{+} / \mathrm{IL}^{-17^{+}}\right.$, figures $\left.2 \mathrm{~A}, \mathrm{C}\right)$ in the groups exposed to DE than in the PBS-exposed group. Tc17 cells $\left(\mathrm{CD} 8^{+} /\right.$ IL-17 ${ }^{+}$, figures $\left.2 \mathrm{~B}, \mathrm{D}\right)$ showed a similar pattern although not statistically significant. IL-17-producing $\gamma \delta \mathrm{T}$ cells were not found (data not shown).

In addition, higher levels of IL-1 $\beta$ and IL-6, cytokines involved in Th17 and Tc17 differentiation were found in lungs of DE-exposed groups compared with the PBS-exposed group (figure 2E,F).

\section{DE exposure induces inflammatory infiltrates and neutrophilic inflammation in mouse lungs}

All types of DE induced numerous mixed inflammatory infiltrates in mouse lungs (figure $3 \mathrm{~A}$ ), which were located perivascularly and peribronchiolarly, as well as in the parenchyma. Immunohistochemistry demonstrated these inflammatory infiltrates to be composed of T and B cells, macrophages and neutrophils (see online supplementary figure S3). Quantification of neutrophils revealed that all types of DE induced lung neutrophilia (figure 3B).

\section{Exposure to $\mathrm{DE}$ does not increase $\mathrm{MCh}$ responsiveness}

To assess whether exposure to DE induces changes in lung function, MCh responsiveness was measured. Exposure to all types of DE did not increase MCh responsiveness (see online supplementary figure S4).

\section{All DEs protect against HDM-induced Th2 responses}

The effect of different types of DE exposure on the HDM-induced Th2 response was determined. HDM exposure increased the levels of Th2 cytokines IL-4, IL-5 and IL-13 in lung tissue, but this increase was not observed in mice exposed to the combination of HDM plus any type of DE (figure 4A-C). Similarly, numbers of eosinophils and levels of HDM-specific IgE were higher in HDM-exposed mice, while these HDM effects were not present in mice exposed to HDM plus each type of DE (figure 4D,E). Mice exposed to HDM had a lower PC200, meaning increased MCh responsiveness, compared with 

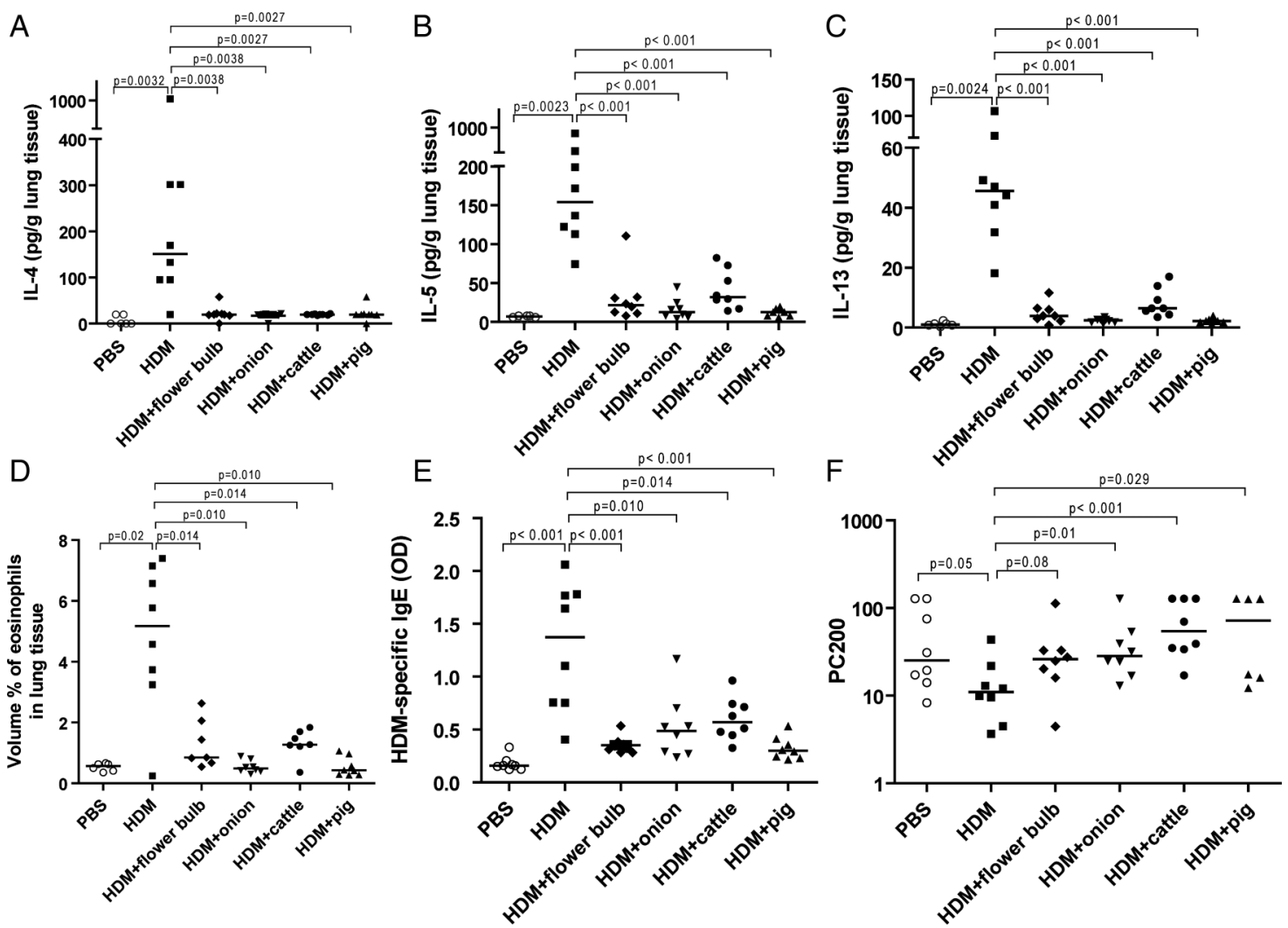

Figure 4 Levels of (A) interleukin (IL)-4, (B) IL-5, (C) IL-13, (D) eosinophils in lung tissue, (E) house dust mite (HDM)-specific IgE in serum and (F) PC200 of mice exposed to phosphate-buffered saline (PBS), HDM or HDM + dust extracts (DEs) derived from cattle or pig farms or flower bulb or onion industries ( $n=6-8$ per group).

PBS-exposed mice (figure 4F). This HDM-induced MCh responsiveness was prevented after DE exposure.

\section{Higher percentages of circulating Th17 and Th1 in AWs}

To translate our studies in mice to the human situation, the different Th-cell subsets were compared between AWs from the same environmental settings as the dust used in the mouse experiments and non-exposed controls. Except for age, the main characteristics of the two study populations did not differ (table 2). The main characteristics were similar for the four AW environments.

Th-cell subsets were defined by simultaneous measurement of the intracellular presence of IL-4, IL-17 and IFN $\gamma$ in $\mathrm{CD} 8^{-} \mathrm{T}$ cells expressing the early activation marker $\mathrm{CD} 69^{+}$and the presence of the transcription factor Foxp3 in $\mathrm{CD}^{-}$activated $\left(\mathrm{CD} 25^{+}\right)$T cells. Please refer to online supplementary figure S5 for gating strategies. Interestingly, AWs had higher frequencies

Table 2 Main characteristics of the study population

\begin{tabular}{lll}
\hline & Healthy controls & Agricultural workers \\
\hline Total number & 9 & 33 \\
Age (years) & $35.5 \pm 20.8$ (range 19-66) & $46.5 \pm 10.6$ (range 29-72) \\
Male gender & $9(100 \%)$ & $33(100 \%)$ \\
Never smokers & $9(100 \%)$ & $33(100 \%)$ \\
BMl & $24.7 \pm 4.5$ & $25.5 \pm 3.0$ \\
FEV $_{1 \% \text { pred. }}$ & $102.4 \% \pm 8.9 \%$ & $106.4 \% \pm 13.6 \%$ \\
FVC $\%$ pred. & $106.7 \% \pm 6.4 \%$ & $110 \% \pm 15.4 \%$ \\
\hline
\end{tabular}

Values are given as mean \pm SD unless otherwise indicated. of $\mathrm{CD} 8^{-} \mathrm{CD} 69^{+} \mathrm{T}$ cells spontaneously expressing IL-17 (Th17) or IFN $\gamma$ (Th1) than controls (figure 5A,B, respectively). In addition, AWs had lower percentages of IL- $4^{+}$cells (Th2) within the $\mathrm{CD}^{-} \mathrm{CD}^{2} 9^{+} \mathrm{T}$ cells compared with controls (figure $5 \mathrm{C}$ ). Since regulatory $\mathrm{T}$ cells (Tregs) play an important role in the downregulation of Th1 and Th2 responses, we investigated the intracellular expression of Foxp 3 within the CD $8^{-} \mathrm{CD} 25^{+}$T-cell population. There was no difference in frequencies of Tregs between AWs and controls (figure 5D).

Stimulation with PMA/Ca-Io increased the frequencies of Th cells expressing IL-17 and IFN $\gamma$ in AWs and controls, resulting in similar numbers of Th17 and Th1 cells for both groups (see online supplementary figure S7). IL-4 expression was not increased after PMA/Ca-Io stimulation and was similar in AWs and controls (data not shown).

\section{Higher percentages of circulating Tc17 and Tc1 in agricultural workers}

Similar to the findings in $\mathrm{CD} 8^{-}$cells, AWs had higher percentages of $\mathrm{CD}^{+}{ }^{+}$T cells spontaneously expressing IL-17 (Tc17) and IFN $\gamma$ (Tc1) than controls (figure 6A,B). Percentages of IL- $4^{+}$cells within the $\mathrm{CD} 8^{+} \mathrm{T}$ cells were not different between both groups (data not shown). Overnight stimulation with PMA/Ionomycin increased the frequencies of $\mathrm{CD}^{+}$cells expressing IL-17 and IFN $\gamma$ in AWs and controls, resulting in similar levels for both groups (see online supplementary figure S7).

\section{DISCUSSION}

This study demonstrates that chronic exposure to different types of DEs induces Th17 responses accompanied by lung neutrophilia and mixed inflammatory infiltrates in mouse lungs. In 

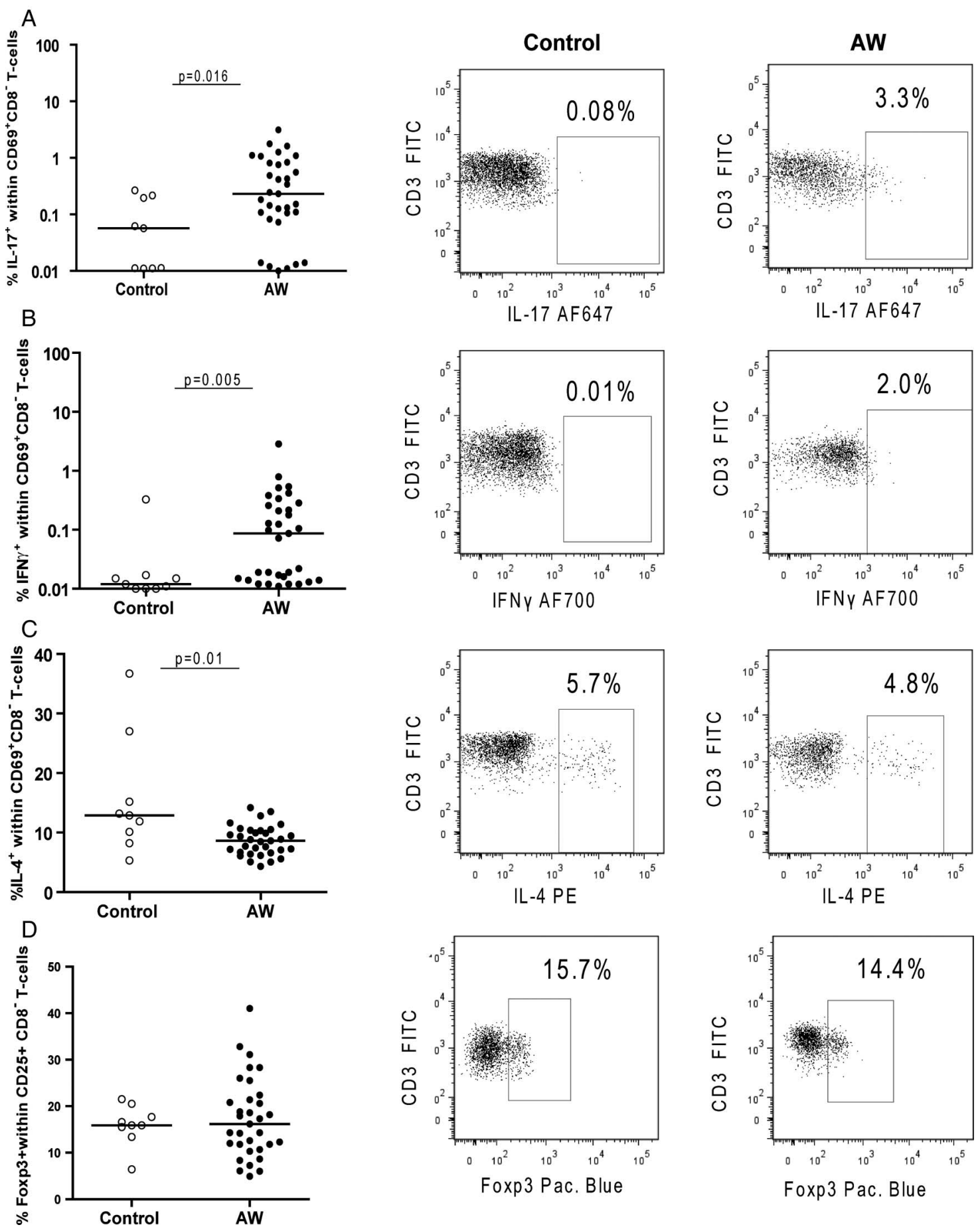

Figure 5 Percentages of circulating (A) interleukin (IL)-17, (B) interferon $\gamma$ (IFN $\gamma$ ) and (C) IL-4 producing CD3 ${ }^{+} \mathrm{CD} 4^{+} \mathrm{CD69} 9^{+}$cells, and (D) percentages of Foxp3-expressing $\mathrm{CD} 3^{+} \mathrm{CD} 4^{+} \mathrm{CD} 25^{+}$cells from controls and agricultural workers (AWs). Representative dot plots of IL-17, IFN $\gamma$, IL-4 expression in $\mathrm{CD}^{+} \mathrm{CD}^{+} \mathrm{CD}^{+} 9^{+}$cells and Foxp3 expression in $\mathrm{CD}^{+} \mathrm{CD}^{+} \mathrm{CD} 25^{+}$cells from controls and AWs are shown.

addition, all types of DEs protected against HDM-induced Th2 responses, that is, airway eosinophilia, HDM-specific $\operatorname{IgE}$ in serum, and IL-4, IL-5 and IL-13 production in the lung tissue. Interestingly, our results from the mouse model are supported by the human data. Occupational organic dust exposure skewed the circulating T-cell population towards the Th17 and Th1 phenotypes compared with controls, while the Treg frequencies were of similar size.

Levels of occupational endotoxin exposure are known to vary greatly depending on the type of work environment or agricultural activity. ${ }^{17}$ Previously, we observed a linear doseresponse relationship between increased endotoxin exposure and a higher risk of respiratory symptoms, ${ }^{17}$ which was dependent on level of exposure but seemed to be independent of work environment. In line with these findings, we show in mice that exposure to DEs from four different agricultural settings induced Th17 differentiation and consequent lung inflammatory infiltrates, and protection against Th2 responses. These settled dust samples are complex mixtures and it is difficult to identify causal agents without considering co-exposure to other relevant 

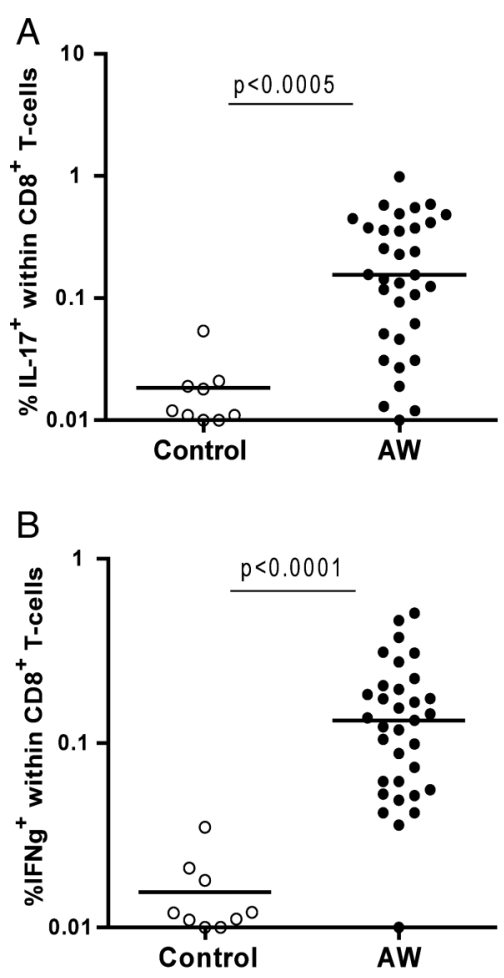
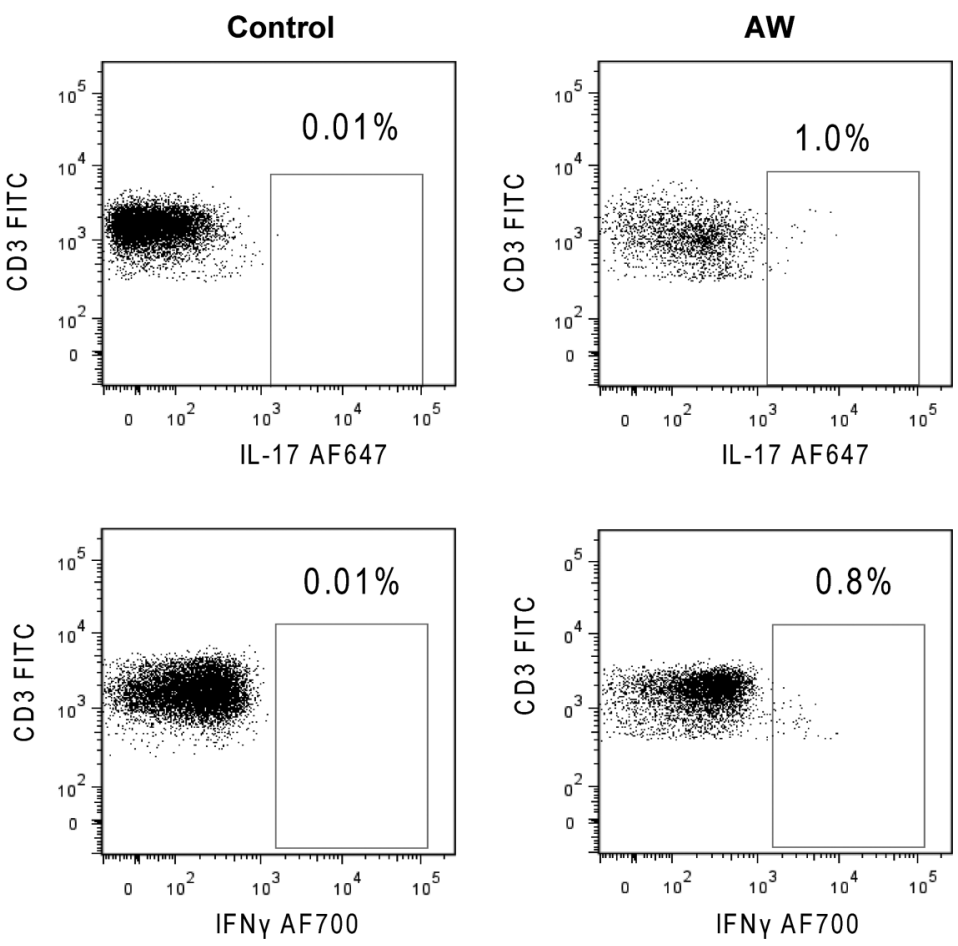

Figure 6 Percentages of (A) interleukin (IL)-17 and (B) interferon $\gamma$ (IFN $\gamma$ )-producing $\mathrm{CD}^{+} \mathrm{CD}^{+}$cells from controls and agricultural workers (AWs). Representative dot plots of IL-17 and IFN $\gamma$ expression in controls and AWs are shown.

agents. In our study, as a result of the extraction procedure of the dust, a bias towards $\mathrm{NaCl}$-soluble components may have occurred.

Exposure of healthy individuals to dusts from agricultural environments has been shown to result in an intense inflammatory response, characterised by high numbers of neutrophils and lymphocytes in bronchial lavage. ${ }^{14} 22$ This response seems to attenuate over time, but repetitive exposures may lead to chronic respiratory disease. ${ }^{2}$ Since IL-17 is known to be involved in the IL-8-dependent attraction of neutrophils to the lung, we hypothesised that IL-17 is involved in the DE-induced inflammatory response. In this study, we showed that chronic exposure to different types of DEs induced IL-17 production in murine lung tissue, which was accompanied by marked lung inflammation. This inflammation was characterised by neutrophilia, inflammatory aggregates, mainly composed of macrophages and $\mathrm{B}$ and $\mathrm{T}$ lymphocytes, and higher levels of additional inflammatory cytokines (IL-1 $\beta$ and IL-6). These findings are in agreement with other mouse studies using pig DEs. ${ }^{23}$ However, the effect of DEs from other types of farms have until now not been described. We show that exposure to other types of DEs induced a similar type of inflammatory response as exposure to pig DE.

We demonstrated the presence of Th17 and Tc17 cells in murine lungs after DE exposure. This indicates that these IL-17-producing T-cell subsets are important in host defence against microbial components present in DE, which is in line with previous studies. ${ }^{25} 26$ Other studies described IL-17 production by $\gamma \delta \mathrm{T}$ cells and neutrophils, ${ }^{27} 28$ which was not observed in our study.

The observed protective effects of DEs in the HDM-induced asthma model support data obtained by previous studies in OVA mouse models for asthma. In these studies, exposure to dust extract, $^{12}$ polysaccharides $^{29}$ and specific microbes ${ }^{30-32}$ isolated from farm cowsheds also protected against OVA-induced allergic airway inflammation. Mechanisms underlying the observed allergy protection in these studies included upregulation of Th1 cells $^{30-32}$ or induction of tolerogenic dendritic cells, ${ }^{12} 29$ as reflected by increased levels of IFN $\gamma$ and IL-10, respectively. IFN $\gamma$ levels were not increased after HDM + DE exposure compared with mice exposed to HDM alone, excluding upregulation of Th1 as the mechanism of protection in our model. Hence, the mechanism of protection in our mouse model remains to be elucidated.

According to the hygiene hypothesis, microbial exposures during childhood are important for the development of a healthy Th1 response, to counterbalance the Th2-biased immune system of newborns. ${ }^{33}$ More recent studies have shown that exposures to a farm environment protect from Th2 responses independently from farm childhood. ${ }^{4}$ We show here that agricultural workers have higher percentages of circulating Th17 and Th1 cells, while the percentage of Th2 cells was lower than in non-exposed controls. These findings support the large amount of literature showing a lower prevalence of Th2-related allergic diseases in farmers and agricultural workers. ${ }^{9} 1117$ Besides the increased percentages of Th17 cells in agricultural workers, the percentages of Tc17 cells, a subset of $\mathrm{CD}^{+} \mathrm{T}$ cells that produces IL-17, were also increased. While a skewing of the immune system towards the Th1 subset seems to be protective against allergic diseases, the increase in circulating $\mathrm{IL}-17^{+}$cells in agricultural workers may be related to the development of chronic respiratory lung disease and possibly related to respiratory infections. ${ }^{25}$ Interestingly, levels of IL-17, IL-17-expressing cells were reported to be increased in human BAL fluid after acute inhalation of organic dust in a pig confinement. ${ }^{14}{ }^{15}$ Although these studies were performed with a low number of individuals (15 and 6, respectively), the induction of IL-17 in BAL indicates that a specific IL-17 response is induced 
by exposure to a farm environment. It should be acknowledged that no female subjects and no smokers were included in our study. It is not known whether differences are to be expected in responses according to gender. As active smoking is known to affect the immune response, we have restricted our population to non-smoking individuals.

Interestingly, differences in T-cell subsets between agricultural workers and healthy controls were only found in unstimulated cells. These cells reflect the actual T-cell phenotype in the host, which indicates that circulating $T$ cells from agricultural workers are different from $\mathrm{T}$ cells in healthy controls. After stimulation with PMA/Ca-Io, higher frequencies of cells expressing the early activation marker CD69 were found and within this population, higher frequencies of $\mathrm{T}$ cells producing IFN $\gamma$ and IL-17. However, after this stimulation, no differences were found between agricultural workers and controls. This can probably be explained by the strong stimulation by the protein kinase $\mathrm{C}$ activator, PMA and the calcium ionophore, which could have induced a plateau in cytokine production in both groups.

In conclusion, this study shows that chronic exposure to various agriculture environments induces a shift in the T-cell population towards a Th17/Th1 phenotype. This may on the one hand protect from allergic disease development as shown in our mouse model, but on the other hand may contribute to other chronic lung disease, as suggested by the lung neutrophilia in the same mouse model. It is clear that the role of IL-17 and Th17 polarisation in the agriculture dust-induced phenotype demands further investigation.

\section{Author affiliations \\ ${ }^{1}$ Department of Pathology, University of Groningen, University Medical Center Groningen, Groningen, The Netherlands \\ ${ }^{2}$ University of Groningen, University Medical Center Groningen, GRIAC-Groningen Research Institute for Asthma and COPD, Groningen, The Netherlands ${ }^{3}$ Division of Environmental Epidemiology, Institute for Risk Assessment Sciences (IRAS), University of Utrecht, Utrecht, The Netherlands \\ ${ }^{4}$ Department of Pharmacokinetics, University of Groningen, Toxicology and \\ Targeting, Groningen, The Netherlands \\ ${ }^{5}$ Department of Pulmonology, University of Groningen, University Medical Center Groningen, University of Groningen, Groningen, The Netherlands \\ ${ }^{6}$ Department of Medical Biology, University of Groningen, University Medical Center Groningen, University of Groningen, Groningen, The Netherlands}

Acknowledgements Pieter Klok and Marco Tibbesma are gratefully acknowledged for their assistance during animal experiments. Jack Spithoven is acknowledged for assistance during dust collection, dust extraction and fieldwork.

Contributions PR, EAJS, CAB, DH, WT, BNM, IMW and MNH contributed to the design and planning of the experiments. PR, EAJS, CD, ET, MvdB and ML conducted fieldwork and laboratory experimental work. PR, EAJS, CAB, DH, WT, BNM, IMW, $\mathrm{MNH}, \mathrm{CD}, \mathrm{ET}, \mathrm{AJMvO}, \mathrm{MvdB}$ and $\mathrm{ML}$ contributed to the reporting of findings and writing the manuscript.

Competing interests the authors declare no competing interests.

Funding This work was supported by grants from the Netherlands Asthma Foundation (grant no. 3.2.09.036) and COST BM1201.

Competing interests Yes.

Ethics approval METC.

Provenance and peer review Not commissioned; externally peer reviewed.

\section{REFERENCES}

1 Thaon I, Thiebaut A, Jochault $L$, et al. Influence of hay and animal feed exposure on respiratory status: a longitudinal study. Eur Respir J 2011;37:767-74.

2 Poole JA, Romberger DJ. Immunological and inflammatory responses to organic dust in agriculture. Curr Opin Allergy Clin Immunol 2012;12:126-32.

3 Eduard W, Pearce N, Douwes J. Chronic bronchitis, COPD, and lung function in farmers: the role of biological agents. Chest 2009;136:716-25.
4 Douwes J, Travier N, Huang $\mathrm{K}$, et al. Lifelong farm exposure may strongly reduce the risk of asthma in adults. Allergy 2007;62:1158-65.

5 Braun-Fahrlander C, Riedler J, Herz U, et al. Environmental exposure to endotoxin and its relation to asthma in school-age children. N Engl J Med 2002;347:869-77.

6 Ege MJ, Mayer M, Normand AC, et al. Exposure to environmental microorganisms and childhood asthma. N Engl J Med 2011;364:701-9.

7 Riedler J, Braun-Fahrlander C, Eder W, et al. Exposure to farming in early life and development of asthma and allergy: a cross-sectional survey. Lancet 2001;358:1129-33.

8 Portengen $\mathrm{L}$, Preller $\mathrm{L}$, Tielen $\mathrm{M}$, et al. Endotoxin exposure and atopic sensitization in adult pig farmers 1. J Allergy Clin Immunol 2005;115:797-802.

9 Smit LA, Heederik D, Doekes G, et al. Occupational endotoxin exposure reduces the risk of atopic sensitization but increases the risk of bronchial hyperresponsiveness. Int Arch Allergy Immunol 2010;152:151-8.

10 Basinas I, Schlunssen V, Heederik D, et al. Sensitisation to common allergens and respiratory symptoms in endotoxin exposed workers: a pooled analysis. Occup Environ Med 2012;69:99-106.

11 Eduard W, Douwes J, Omenaas E, et al. Do farming exposures cause or prevent asthma? Results from a study of adult Norwegian farmers. Thorax2004;59:381-6.

12 Peters $\mathrm{M}$, Kauth $\mathrm{M}$, Schwarze J, et al. Inhalation of stable dust extract prevents allergen induced airway inflammation and hyperresponsiveness. Thorax 2006;61:134-9.

13 Poole JA, Gleason AM, Bauer C, et al. alphabeta T cells and a mixed Th1/Th17 response are important in organic dust-induced airway disease. Ann Allergy Asthma Immunol 2012;109:266-73.e2.

14 Laan M, Palmberg L, Larsson K, et al. Free, soluble interleukin-17 protein during severe inflammation in human airways. Eur Respir J 2002;19:534-7.

15 Ivanov S, Palmberg L, Venge $P$, et al. Interleukin-17A mRNA and protein expression within cells from the human bronchoalveolar space after exposure to organic dust. Respir Res 2005;6:44.

16 Ano S, Morishima Y, Ishii Y, et al. Transcription factors GATA-3 and RORgammat are important for determining the phenotype of allergic airway inflammation in a murine model of asthma. J Immunol 2013;190:1056-65.

17 Smit LA, Heederik D, Doekes G, et al. Exposure-response analysis of allergy and respiratory symptoms in endotoxin-exposed adults 1. Eur Respir J 2008;31:1241-8.

18 Spaan S, Schinkel J, Wouters IM, et al. Variability in endotoxin exposure levels and consequences for exposure assessment. Ann Occup Hyg 2008;52:303-16.

19 Douwes J, Siebers R, Wouters I, et al. Endotoxin, (1 -> 3)-beta-D-glucans and fungal extra-cellular polysaccharides in New Zealand homes: a pilot study. Ann Agric Environ Med 2006;13:361-5.

20 Hamelmann E, Schwarze J, Takeda K, et al. Noninvasive measurement of airway responsiveness in allergic mice using barometric plethysmography. Am J Respir Crit Care Med 1997;156:766-75

21 Blacquiere MJ, Timens W, Melgert BN, et al. Maternal smoking during pregnancy induces airway remodelling in mice offspring. Eur Respir J 2009;33:1133-40.

22 Larsson BM, Palmberg L, Malmberg PO, et al. Effect of exposure to swine dust on levels of IL-8 in airway lavage fluid. Thorax 1997:52:638-42.

23 Poole JA, Wyatt TA, Kielian T, et al. Toll-like receptor 2 regulates organic dust-induced airway inflammation. Am J Respir Cell Mol Biol 2011;45:711-19.

24 Poole JA, Wyatt TA, Oldenburg PJ, et al. Intranasal organic dust exposure-induced airway adaptation response marked by persistent lung inflammation and pathology in mice. Am J Physiol Lung Cell Mol Physiol 2009;296:L1085-95.

25 Hamada H, Garcia-Hernandez Mde L, Reome JB, et al. TC17, a unique subset of CD8 T cells that can protect against lethal influenza challenge. J Immunol 2009;182:3469-81.

26 Kolls JK, Khader SA. The role of Th17 cytokines in primary mucosal immunity. Cytokine Growth Factor Rev 2010;21:443-8.

27 Murdoch JR, Lloyd CM. Resolution of allergic airway inflammation and airway hyperreactivity is mediated by IL-17-producing \{gamma\}\{delta\}T cells. Am J Respir Crit Care Med 2010;182:464-76.

28 Ferretti S, Bonneau O, Dubois GR, et al. IL-17, produced by lymphocytes and neutrophils, is necessary for lipopolysaccharide-induced airway neutrophilia: IL-15 as a possible trigger. J Immunol 2003;170:2106-12.

29 Peters $\mathrm{M}$, Kauth $\mathrm{M}$, Scherner 0 , et al. Arabinogalactan isolated from cowshed dust extract protects mice from allergic airway inflammation and sensitization. J Allergy Clin Immunol 2010;126:648-56.e1-4.

30 Debarry J, Garn H, Hanuszkiewicz A, et al. Acinetobacter Iwoffii and Lactococcus lactis strains isolated from farm cowsheds possess strong allergy-protective properties. J Allergy Clin Immunol 2007;119:1514-21.

31 Debarry J, Hanuszkiewicz A, Stein K, et al. The allergy-protective properties of Acinetobacter Iwoffii F78 are imparted by its lipopolysaccharide. Allergy 2010:65:690-7.

32 Vogel K, Blumer N, Korthals M, et al. Animal shed Bacillus licheniformis spores possess allergy-protective as well as inflammatory properties. J Allergy Clin Immunol 2008;122:307-12, 312.e1-8.

33 Strachan DP. Hay fever, hygiene, and household size. BMJ 1989;299:1259-60. 